\title{
Norwegican Cartilage Project - a study protocol for a double-blinded randomized controlled trial comparing arthroscopic microfracture with arthroscopic debridement in focal cartilage defects in the knee
}

Tommy Frøseth Aae ${ }^{1 *}$, Per-Henrik Randsborg ${ }^{2}$, Anne Berg Breen ${ }^{3}$, Håvard Visnes $^{4}$, Søren Vindfeld ${ }^{5}$, Einar Andreas Sivertsen ${ }^{6}$, Sverre Løken ${ }^{7}$, Jan Brinchmann ${ }^{8}$, Heidi Andreassen Hanvold ${ }^{9}$ and Asbjørn Årøen ${ }^{10,11}$

\begin{abstract}
Background: Focal lesions to the articular cartilage in the knee might have demolishing consequences to the knee. There exists a wide range of possible surgical procedures targeting these injuries, however no significant differences have been found between these procedures. This may support that the improvement is a result of rehabilitation, and not the surgery itself. Arthroscopic microfracture (MF) treatment has gained popularity, and has become the treatment of choice in patients with knee cartilage defects globally. In this study we want to increase knowledge, both clinical and economic, about arthroscopic microfracture (AF) compared to arthroscopic debridement (AD) and physical rehabilitation both in the short run, and in the long run.

Methods/Design: To compare arthroscopic microfracture with arthroscopic debridement and physiotherapy for the treatment of focal cartilage lesions in the knee, a long-term, double-blinded, randomized controlled multicenter trial will be conducted. A total of 114 men and non-pregnant women with a symptomatic focal full thickness cartilage lesion in the knee less than $2 \mathrm{~cm} 2$ will be included in the study. The two treatment allocations will receive identical rehabilitation, which is made up of 3 phases: accommodation, rehabilitation and return to activity. Follow up is 24 months, where all will be invited to participate in late follow ups after 5 and 10 years.

The Knee Injury and Osteoarthritis Outcome Score (KOOS) knee-related quality of life (QoL) subscore is the primary endpoint. Clinical parameters, questionnaires and radiologic modalities (Magnetic Resonance Imaging (MRI) and xray) will be used as secondary endpoints.
\end{abstract}

Discussion: This is an ongoing multicenter study with a high level of evidence to compare arthroscopic microfracture with arthroscopic debridement and physiotherapy for the treatment of isolated symptomatic full thickness cartilage lesions in the knee joint.

Trial registration: ClinicalTrials.gov ID: NCT02637505 (December 15, 2015).

\footnotetext{
* Correspondence: tommy.aae@gmail.com

${ }^{1}$ Department of Orthopedic Surgery, Kristiansund Hospital, Kristiansund,

Norway

Full list of author information is available at the end of the article
}

\section{Biomed Central}

(c) 2016 The Author(s). Open Access This article is distributed under the terms of the Creative Commons Attribution 4.0 International License (http://creativecommons.org/licenses/by/4.0/), which permits unrestricted use, distribution, and reproduction in any medium, provided you give appropriate credit to the original author(s) and the source, provide a link to the Creative Commons license, and indicate if changes were made. The Creative Commons Public Domain Dedication waiver (http://creativecommons.org/publicdomain/zero/1.0/) applies to the data made available in this article, unless otherwise stated. 


\section{Background}

Articular cartilage is highly specialized tissue in joints, with main functions to provide lubrication to the joint and load shearing. Since the hyaline cartilage covering the articular surface is devoid of blood vessels, lymphatic drainage and nerves, very limited intrinsic healing capacity exist [1-3]. Focal lesions to the articular cartilage in the knee might have demolishing consequences to the knee both in the short term and in the long term, due to the predisposition of early onset osteoarthritis. With a prevalence of $12 \%$ in young adults, focal cartilage lesions are common [4]. Musculoskeletal disorders (MSDs) are the most common occupational disease in the European Union. Workers in all sectors and occupations can be affected, and this may have a major impact both socially and not least financially [5-8]. With this in mind, treatment of symptomatic articular cartilage lesions is of great interest to those who prevent and treat MSDs, as well as the patient and the society $[3,9,10]$.

All types of articular cartilage repair procedures aim to repair cartilage whilst keeping options open for alternative treatments in the long term. The most common surgical interventions are arthroscopic debridement, bone marrow techniques with or without augmentation with stem cells (including microfracture and autologous matrix-induced chondrogenesis), osteochondral transplantation (autografts and allografts), cell based repairs (autologous chondrocyte implantation (ACI) and autologous mesenchymal stem cell transplant [11-13].

Arthroscopic debridement (AD) focusses on removing loose articular flaps and fibrous tissue to the subchondral bone [12]. Arthroscopic microfracture (AM) includes an $\mathrm{AD}$ procedure followed by drilling holes (micofractures) through the subchondral bone using an awl. This generates a blood clot (called a super-clot) which becomes fibrocartilage over time and fills the articular cartilage defect [12]. Improved knee function have been reported in some studies [14], but they have been criticized for weakness in methodology [15].

None of the various options for focal cartilage injuries have been able to demonstrate a superior outcome when compared to each other in randomized controlled trials, suggesting that the strict post-operative rehabilitation common for all techniques are more important to the clinical improvement than the cartilage surgery itself $[16,17]$.

Due to its minimally invasive approach, technical simplicity and low costs, microfracture treatment has gained popularity over the past decades, and has become the treatment of choice in patients with knee cartilage defects [18-23]. Microfracture is most likely not effective for larger lesions [22, 24-26], and is currently recommended for lesions below 2-4 $\mathrm{cm}^{2}$ [27-30]. Meta-analysis and systematic reviews have required well-designed, long-term, multicenter studies to evaluate clinical outcomes of microfracture with the use of a "no treatment" group as a control group to increase knowledge, both clinical and economic, about arthroscopic microfracture compared to arthroscopic debridement in the short and long run $[10,25,26,31,32]$.

\section{Purpose}

Comparing arthroscopic microfracture (AM) with arthroscopic debridement (AD) in patients with symptomatic full thickness knee cartilage defects less than $2 \mathrm{~cm}^{2}$ in the knee joint is the purpose of this study. The aims will be differences both in regard of subjective and objective variables at predefined times up to 24 months follow up.

\section{Methods and design}

The study emanates from "The Norwegian Cartilage Project" (NCP). The NCP is a Norwegian project organization with a goal of improving the treatment of injured articular cartilage in the knee through five studies. The study protocol is written in collaboration with the authors behind the already published study protocol regarding ACI and debridement [33].

This multicenter study with 2 treatment arms (AM and $\mathrm{AD}$ ) is designed as a prospective, randomized, double-blinded parallel study, see Fig. 1. The study will be conducted at Norwegian hospitals including Kristiansund Hospital, Haukeland University Hospital, Ålesund Hospital, Diakonhjemmet Hospital, Haraldsplass Deaconess Hospital, Oslo University Hospital - Ullevål and Akershus University Hospital. Each hospital will have a member of the NCP group as a local coordinator. The sponsor of the study is Akershus University Hospital, with sponsor representative professor Asbjørn Årøen.

Inclusion, treatment and follow-up of the patients will be done at the orthopedic clinic at each of the above mentioned hospitals. To secure double blinding at the 24 months follow up, the control will be performed by an external reviewer connected to the NCP group. Follow up is 24 months, but all will be invited to controls at 5 and 10 years respectively.

\section{Participants}

A total of 114 non-pregnant women and men with the age between 18-50 years old will be enrolled in the study, with a cartilage defect up to $2 \mathrm{~cm}^{2}$ in the femoral condyles or trochlea. By using a Lysholm score less than 75 [34], we only include symptomatic defects in the study. Included patients will have normal alignment (varus or valgus less than $5^{\circ}$ measured clinically and if uncertainty, on hipknee-ankle (HKA) angle images), normal range of motion (ROM) (minimum $5-105^{\circ}$ ), a stable knee with no sign of radiologically osteoarthritis [35] obtained with the SynaFlex X-ray positioning frame [36]. The inclusion criteria 


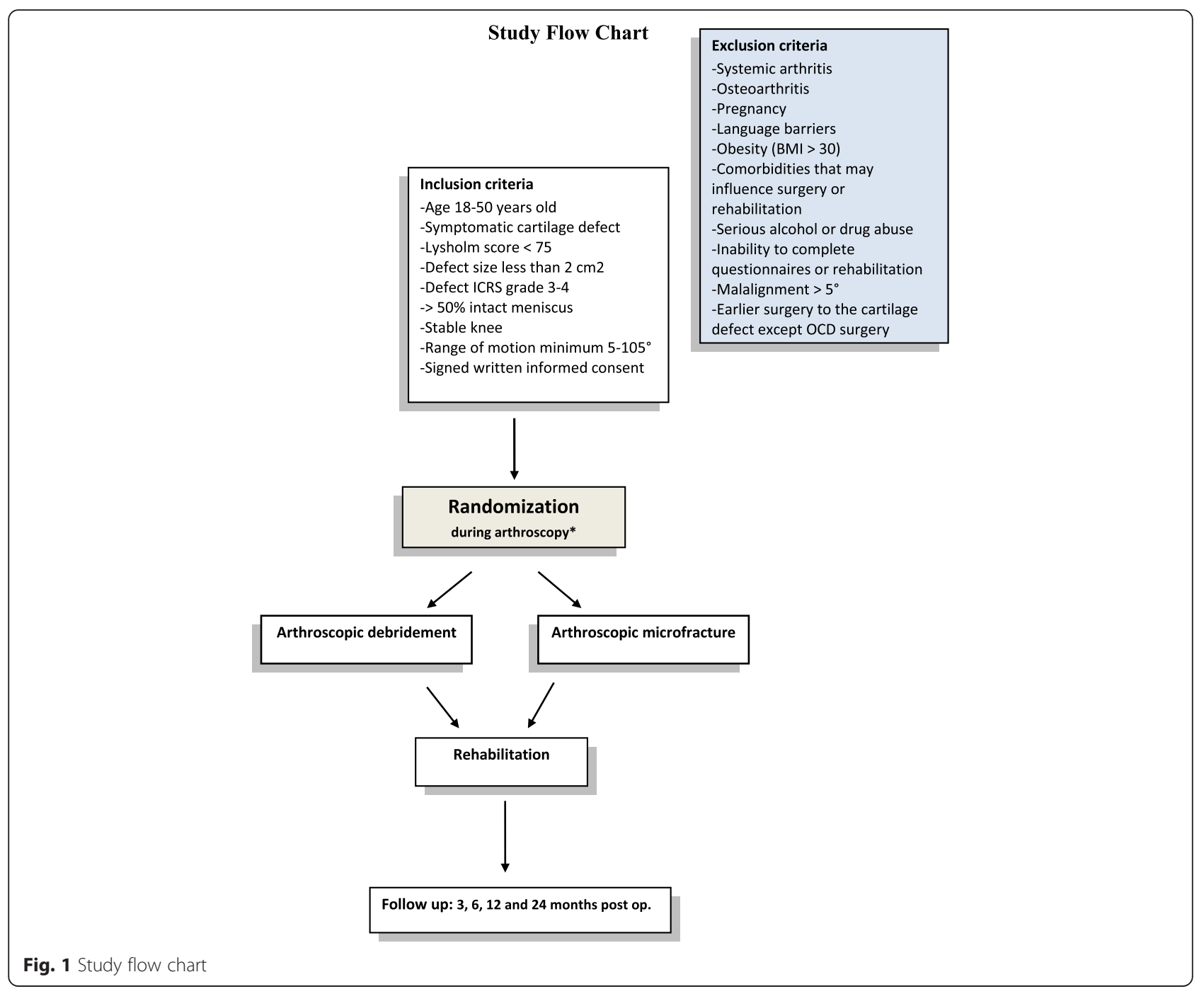

are based on Steadman et al, Saris et al and Ulstein et al $[22,37,38]$. Prior to inclusion, written informed consent will be obtained from all subjects.

All patients will, prior to inclucion, be assessed clinically and radiologically. Using the International Cartilage Repair Society (ICRS) grading system of cartilage defects, the defect will be verified arthroscopically as a grade 3 or 4 [39]. Peroperatively arthroscopic findings such as inappropriate size of the lesion, osteoarthritis or less than $50 \%$ normal meniscus will lead to preoperatively exclusion [40]. The operating surgeon will perform definitive inclusion of the patient in the study. According to the standard at the local hospital, excluded patients will receive appropriate treatment.

Systemic arthritis, osteoarthritis, pregnancy, language barriers, severe obesity (body mass index $>30$ ), comorbidities that may influence surgery or rehabilitation, alcohol, substance or drug abuse, inability to complete questionnaires or rehabilitation and psychiatric disorders are exclusion criteria, see Table 1 . Previous surgery to the cartilage defects except debridement and fixation of osteochondritis dissecans lesions are also exclusion criteria. Previous alignment procedures, cruciate ligament reconstruction and meniscus surgery are not criteria for exclusion. Those who withdraw during the trials or declining enrollment will be treated according to the standard of care.

\section{Blinding and randomization}

The study is designed as a double blinded study. As long as the trial lasts, the patients will not verbally nor written be informed which treatment is given to them. The operating surgeon will not be blinded, but will not be involved in the follow ups. Doctors involved in follow ups will be blinded for the given treatment. When patients are completing the questionnaires during follow ups, the case report forms (CRF) will not contain any information of the given treatment. The follow up at 24 months 
Table 1 Inclusion and exclusion criteria

\begin{tabular}{ll}
\hline Inclusion criteria & Exclusion criteria \\
\hline -Age 18-50 years old & - Systemic arthritis \\
-Symptomatic cartilage defect & - Osteoarthritis \\
-Lysholm score $<75$ & - Pregnancy \\
-Defect size less than $2 \mathrm{~cm}^{2}$ & - Language barriers \\
-Lesion graded ICRS 3-4 & - Obesity (BMI $>30$ ) \\
- $>50 \%$ intact meniscus & - Comorbidities that may influence \\
-Stable knee & surgery or rehabilitation \\
-Range of motion 5-105 & - Serious alcohol or drug abuse \\
-Signed written informed & - Inability to complete questionnaires \\
consent & or rehabilitation \\
& - Malalignment $>5^{\circ}$ \\
& - Earlier surgery to the chondral defect \\
& excluding OCD surgery \\
\hline
\end{tabular}

will be performed at each of the hospitals by an external reviewer connected to the NCP group to secure double blinding at 24 months follow up. The analysis of X-rays after 24 months will be done by an orthopaedic surgeon and a study radiologist, both blinded for the given treatment. The MRI at 24 months will be analyzed by the same blinded study radiologist.

By using a computer generator (randomization.com), the 114 participants will be randomized in blocks of sixeight (1:1) according to treatment allocations. All included participants will be given a number from 1 to 114 on inclusion. Concealed in opaque numerically marked envelopes, randomization will be printed in faded text. An employee at Kristiansund Hospital, not involved in the study, will administer the printing and concealing. The randomization will be done in the operation room during surgery, after the lesion has been graded and measured by the operating surgeon (see section "Operative procedure").

\section{Arthroscopic procedure}

No tourniquet is used. Three standard incisions are made. The procedure starts with a diagnostic arthroscopic examination to verify that the inclusion criteria are present. Any other necessary procedures (plica, meniscus, removal of loose bodies) are performed. Removal of lose and marginally attached cartilage is then done. Thereafter, the cartilage lesion is classified according to the ICRS classification, and measured using a standard 4- $\mathrm{mm}$ arthroscopic probe $[39,40]$. The randomization is performed at the end of the arthroscopy (see section "Blinding and randomization) and the lesion will either undergo arthroscopic debridement (AD) or arthroscopic microfracture (AM).

\section{Arthroscopic debridement}

The lesion is stabilized, debriding all loose or marginally attached cartilage from the surrounding rim to form a stable edge of healthy cartilage around the defect using a ring curette, where cartilage slops down to the defect.

\section{Arthroscopic microfracture}

The cartilage is cut sharp forming a rim of $90^{\circ}$. The calcified layer is removed using a curette before an arthroscopic awl is used to perform multiple holes ("microfractures") from the periphery towards the center. The microfractures are 3-4 $\mathrm{mm}$ apart and 2-4 $\mathrm{mm}$ deep into the subchondral bone. The correct and successful technique is confirmed by direct observation of marrow fat droplets exiting the microfracture as the fluid pump is reduced.

The instruments are removed and the incisions are sutured. Since local anesthetics may have a harmful effect on cartilage, intra-articular local anesthetics will not be used [41-43]. These surgical principles follow the techniques by Steadman and Mithoefer [24, 44-46]. Before study start, all surgeons will be given proper training in the arthroscopic study procedure.

\section{Post-operative protocol}

Identical postoperative care will be given, usually with hospital admission up to 4 days. If there is a risk of thromboembolic disease, anti-thrombotic prophylaxis is given. Prophylactic antibiotic is not given. Up to 2 weeks of sick leave after the operation is given all participants. Any complications that should occur will be managed in a prompt manner by the involved departments.

\section{Rehabilitation protocol}

All patients will be subjected to the same postoperative rehabilitation protocol, based on the work by Wondrasch et al [17]. The rehabilitation program will be headed by a designated study physiotherapist along with the patient's local physiotherapist. The rehabilitation protocol involves three phases: accommodation, rehabilitation and return to activity, and is identical to the rehabilitation protocol in the previous mentioned ACI study [33], see Table 2.

A designated hospital physiotherapist and the surgeon will on the first postoperative day instruct the patients in range of motion exercises and gait training according to Phase 1. Within two weeks of surgery, the patient is seen by a local physiotherapist, who will supervise the rehabilitation program in liaison with the study physiotherapist.

The rehabilitation program includes both active rehabilitation and patient education, and consists primarily of knee/hip progressive resistance, neuromuscular training and cardiovascular resistance, including plyometric exercises and balance. During the physiotherapy, the patients will be explained how to perform the exercises and why they are important, adjusted to pain or other symptoms.

All patients are asked to use training diaries to provide information about the training habits. Additionally, every second week patients are asked to respond to an online survey consisting of 4 questions, all with both predefined answers (closed answers) and open answers available. 
Table 2 Rehabilitation protocol (identical for both groups)

\begin{tabular}{|c|c|c|c|}
\hline Rehabilitation phases & Objectives & Physiotherapy and activities & Criteria for progression to next phase \\
\hline $1^{\text {st }}$ phase: Accomodation & $\begin{array}{l}\text { - Reduce symptoms }{ }^{a} \\
\text { - Normalize ROM og } \\
\text { muscle control }\end{array}$ & $\begin{array}{l}\text { - Education/coaching } \\
\text { - ROM, isometric exercises } \\
\text { - Gait training (no weight-bearing } \\
\text { for two weeks) }\end{array}$ & $\begin{array}{l}\text { - No symptoms during ADL } \\
\text { - Flexion } 90^{\circ} \\
\text { - Normalized quadriceps }\end{array}$ \\
\hline $2^{\text {nd }}$ phase: Rehabilitation & $\begin{array}{l}\text { - Full ROM } \\
\text { - Normalize muscle strength } \\
\text { and joint stability }\end{array}$ & $\begin{array}{l}\text { - Stationary bike cycling } \\
\text { - Progressive knee and hip } \\
\text { resistance training } \\
\text { - Neuromuscular training }\end{array}$ & $\begin{array}{l}\text { - Full ROM } \\
\text { - No symptoms after training } \\
\text { - Equally distributed weight on the lower } \\
\text { limbs during weight-bearing exercises } \\
\text { - Ability to stand on } 1 \text { limb on a flat surface } \\
\text { for at least } 10 \mathrm{~s}\end{array}$ \\
\hline $3^{\text {rd }}$ phase: Return to activity & $\begin{array}{l}\text { - Recovery of strength and } \\
\text { neuromuscular control } \\
\text { - Return to activity/sport }\end{array}$ & $\begin{array}{l}\text { - Knee and hip resistance training } \\
\text { - Neuromuscular training } \\
\text { - Cardiovascular training }\end{array}$ & $\begin{array}{l}\text { - Return to activity/sport based on individual } \\
\text { assessment }\end{array}$ \\
\hline
\end{tabular}

a Symptoms = pain and swelling

The training dairy will be continued till the end of the project (24 months), while the online survey continues as long as the patients are under supervision of a physiotherapist.

$1^{\text {st }}$ phase - Accomodation:

During admission in hospital, the leg is placed in a continunous passive motion (CPM) machine as tolerated, aiming to achieve $30-70^{\circ}$ on the first postoperative day. The CPM should be used up to 6-8 h every $24 \mathrm{~h}$ during the hospital stay.

For the first two weeks, only touch-down weightbearing using crutches is allowed. The patients are encouraged to continue range of motion exercises, existing of 500 knee extensions/flexions three times a day, after discharge from hospital. Each patient should be scheduled to 2 to 3 supervised physical therapy sessions. When the wound is healed, swimming is allowed.

Passing two weeks, weight-bearing as tolerated is carefully introduced, and gradually increased up to full weight-bearing. When the patient walks normal with limping, crutches are not needed.

$2^{\text {nd }}$ phase - Rehabilitation:

The patients perform 1-2 unsupervised training sessions per week, and attend at least 2 supervised physical therapy sessions. Exercises are performed with the uninjured and injured limb. Walking with increasing distances is encouraged, and when full weight-bearing is achieved, cross-country skiing can be allowed.

$3^{\text {rd }}$ phase - Return to activity/sport:

The patients perform unsupervised resistance training for a minimum of 2 and a maximum of 4 sessions per week, and attend at least 1 supervised physical therapy sessions per week. According to the goals for each patient, this phase is individualized. If return to sport is planned, sport-specific activities are included as functional progressions in the rehabilitation protocol.

\section{Outcome measures}

Outcome measures will be the same as the endpoints in an earlier mentioned RCT coming from the same NCP group [33], enabling a direct comparison in outcome.

\section{Demographics}

Age, gender, nationality, social status, work status, use of medication, prior medical history height in $\mathrm{cm}$, weight in $\mathrm{kg}$, Body Mass Index (BMI) and injury mechanism (if any) are collected at inclusion.

\section{Endpoints}

The Knee Injury and Osteoarthritis Outcome Score (KOOS) knee-related quality of life (QoL) subscore is the primary endpoint. Validated to use in cartilage research studies, KOOS is a patient reported outcome measure [47], and will enable comparison of our results with other knee cartilage studies. At 24 months follow up, the difference in KOOS QoL subscore in the AM group compared to the $\mathrm{AD}$ group is the primary aim. No interim analysis is planned.

Clinical parameters, questionnaires and radiologic modalities will be used as secondary endpoints at predefined times at 3 months ( \pm 2 weeks), 6 months ( \pm 4 weeks), 12 months $( \pm 6$ weeks) and 24 months ( \pm 8 weeks). They include range of motion (ROM) measured with a goniometer, visual analogue scale (VAS), all KOOS subscores except knee-related QoL, Tegner score, Lysholm score and EQ-5D. The difference between the two treatment groups and within the group will be the secondary aims. Information about work (return to work), physical activity and return to sport will also be collected.

Additionally, at the follow up after 24 months, a hop test validated by Reid [48], standing radiographs and MRI will be done. All participants will be invited to late follow ups after 5 and 10 years respectively. 


\section{Hypothesis}

Null hypothesis: There is no difference in KOOS QoL following $\mathrm{AM}$ or $\mathrm{AD}$ treatment of a symptomatic full thickness knee cartilage defect less than $2 \mathrm{~cm}^{2} 24$ months after surgery.

Alternative hypothesis: There is a difference in KOOS QoL following AM or AD treatment of a symptomatic full thickness knee cartilage defect less than $2 \mathrm{~cm}^{2} 24$ months after surgery.

\section{Statistical analysis}

Demographic variables will be presented as mean \pm standard deviation (SD) for continuous variables, and frequencies for categorical variables. The normal distribution of the variables will be tested. Given normal distribution, the statistical analysis will be performed using linear mixed models (LMM), including a random center effect for hospital. The test for the primary objective of comparing KOOS QoL from baseline to 24 months between the groups can be performed as a post hoc $t$-test following the LMM. If the data is not normally distributed, a non-parametric analysis will be done using the Mann-Whitney $U$-test. To evaluate the efficacy of treatment in terms of categorical outcome measures we plan to use Chi-squared tests. To adjust for possible confounders such as age of the patient and severity of the cartilage lesion, these variables will be included in the LMM. A $p<0,05$ is considered statistically significant. The statistical analysis will be conducted in collaboration with a statistician at Unit for Applied Clinical Research at Norwegian University of Science and Technology, using SPSS v.22 (SPSS Inc, Chicago, Illinois) and R [49].

\section{Sample size}

A difference in KOOS QoL subscore of 8-10 has previously been shown to be clinically significant [50,51]. With $80 \%$ power comparing the two treatment groups 24 months after surgery by a two-sample $t$-test, power analyses is therefore based on detecting a difference of 10. Using a standard deviation (SD) of 18 ([37, 50] http://www.koos.nu/koosfaq.html), this yields 52 patients in each group. By adding $10 \%$ due to drop out and loss to follow-up, a total of 114 patients will be included.

\section{Risk assessments}

Participants may find it discomforting and unpleasant when they are asked about demographic information. The treatment of choice in this patient category is an arthroscopic operation, so no additional risks exists in participating this study. With a frequency $<1 \%$, these risks is rare and include arthralgia, joint effusion/swelling deep vein thrombosis (DVT), infection, headache and nasopharyngitis. Both treatments (AD and $A M$ ) have a risk of failure, and some might be in need of further surgery.

If any complication occurs during surgery, postoperative management and rehabilitation, patients will be examined by the doctor on call and treated according to clinical guidelines.

\section{Discussion}

The treatment of isolated articular cartilage lesions of the knee is an orthopaedic puzzle, with numerous surgical techniques. Arthroscopic microfracture treatment has become the treatment of choice in patients with knee cartilage defects, but current knowledge is hampered by the lack of well-designed randomized studies comparing the effect of microfracture with debridement alone. This study will answer some of the questions regarding the benefit of AM compared to physical rehabilitation alone, and the results may help surgeons improve clinical outcome after articular cartilage injuries of the knee.

\section{Abbreviations \\ $A C l$, autologous chondrocyte implantation; $A D$, arthroscopic debridement; ADL, activity of daily living; AHUS, Akershus University Hospital; AM, arthroscopic microfracture; $\mathrm{BMI}$, body mass index; Cl, confidence interval; CPM, continuous passive motion; CRF, case report form; DVT, deep vein thrombosis; EQ5D, european quality of life five dimensions; HKA, hip knee ankle; ICRS, International Cartilage Repair Society; ISF, investigator site file; ISPOR, International Society for Pharmacoeconomics and Outcomes Research; KOOS, knee injury and osteoarthritis outcome score; LMM, linear mixed models; MRI, magnetic resonance imaging; MSDs, musculoskeletal disorders; NCP, Norwegian Cartilage Project; OCD, osteochondritis dissicans; PROMS, patient reported outcome measures scores; QoL, quality of life; RCT-CEA, randomized clinical trial-cost-effectiveness analysis; ROM, range of motion; SD, standard deviation; SPSS, Statistical Package for the Social Sciences; VAS, visual analogue scale}

\section{Acknowledgements}

We thank Turid Follestad for statistical assistance. Nina Mickelson Weldingh has provided secretarial support, and is monitoring the study in collaboration with Katarina Mølsæter. We also want to thank Myrthle Hoel for secretarial support.

\section{Funding}

Funded by research grants from the Norwegian Research Council, already awarded NCP, grant number 2015107.

Availability of data and materials

Not applicable owing to the article type.

Authors' contributions

TFA performed literature search, drafted and edited the study protocol. PHR lead the project group and co-drafted and co-edited the protocol. $\mathrm{HAH}$ described and modified the rehabilitation protocol. EAS performed the power analysis. ABB, SV, HV, JB, EAS and SL participated actively in overall study design, including choice of outcome measures, operation technique and follow up algorithm. AA gave critical review of the manuscript and provided funding. All authors read and approved the final manuscript.

\section{Competing interests}

The authors declare that they have no competing interests.

Consent for publication

Not applicable. 


\section{Ethics approval and consent to participate}

The study will be conducted in accordance with ethical principles in the Declaration of Helsinki and are consistent with $\mathrm{ICH} / \mathrm{Good}$ Clinical Practice. The study will have two monitors, and registration of patient data will be carried out in accordance with national personal data laws. The Regional Committee for Medical and Health Research Ethics North-Norway has given the study ethical approval (approval number 2015/2202), and the study is registered on clinicaltrials.gov (ID: NCT02637505).

\section{Author details}

'Department of Orthopedic Surgery, Kristiansund Hospital, Kristiansund, Norway. ${ }^{2}$ Department of Orthopedic Surgery, Akershus University Hospital, Lørenskog, Norway. ${ }^{3}$ Department of Orthopedic Surgery, Ålesund Hospital, Ålesund, Norway. ${ }^{4}$ Department of Orthopedic Surgery, Haukeland University Hospital, Bergen, Norway. ${ }^{5}$ Department of Orthopedic Surgery, Haraldsplass Deaconess Hospital, Deaconess, Norway. ${ }^{6}$ Department of Orthopedic Surgery, Diakonhjemmet Hospital, Diakonveien, Norway. ${ }^{7}$ Department of Orthopedics, Oslo University Hospital, Oslo, Norway. ${ }^{8}$ Department of Immunology and Norwegian Center for Stem Cell Research, Oslo University Hospital, Rikshospitalet, Oslo, Norway. ${ }^{9}$ Department of Physiotherapy, Akershus University Hospital, Lørenskog, Norway. ${ }^{10}$ Institute of Clinical Medicine, University of Oslo, Oslo, Norway. ${ }^{11}$ Oslo Sports Trauma Research Centre, Norwegian School of Sport Sciences, Oslo, Norway.

Received: 8 June 2016 Accepted: 2 July 2016

Published online: 16 July 2016

\section{References}

1. Frisbie DD, Oxford JT, Southwood L, Trotter GW, Rodkey WG, Steadman JR, Goodnight JL, Mcllwraith CW. Early events in cartilage repair after subchondral bone microfracture. Clin Orthop Relat Res. 2003;407:215-27.

2. Ossendorf C, Kaps C, Kreuz PC, Burmester GR, Sittinger M, Erggelet C. Treatment of posttraumatic and focal osteoarthritic cartilage defects of the knee with autologous polymer-based three-dimensional chondrocyte grafts: 2-year clinical results. Arthritis Res Ther. 2007;9(2):R41.

3. Bedi A, Feeley BT, Williams 3rd RJ. Management of articular cartilage defects of the knee. J Bone Joint Surg Am. 2010;92(4):994-1009.

4. Basad E, Ishaque B, Bachmann G, Stürz H, Steinmeyer J. Matrix-induced autologous chondrocyte implantation versus microfracture in the treatment of cartilage defects of the knee: a 2-year randomised study. Knee Surg Sports Traumatol Arthrosc. 2010;18(4):519-27.

5. Messner K, Gillquist J. Cartilage repair. A critical review. Acta Orthop Scand. 1996;67(5):523-9.

6. Løken S, Heir S, Holme I, Engebretsen L, Årøen A. 6-Year follow-up of 84 patients with cartilage defects in the knee. Knee scores improved but recovery was incomplete. Acta Orthop. 2010;81(5):611-8.

7. Minas T, Nehrer S. Current concepts in the treatment of articular cartilage defects. Orthopedics. 1997;20:525-38

8. Prakash D, Learmonth D. Natural progression of osteo-chondral defect in the femoral condyle. Knee. 2002;9(1):7-10.

9. Steadman JR, Hanson CM, Briggs KK, Matheny LM, James EW, Guillet A. Outcomes after knee microfracture of chondral defects in alpine ski racers. J Knee Surg. 2014;27(5):407-10.

10. Goyal D, Keyhani S, Lee EH, Hui JH. Evidence-based status of microfracture technique: a systematic review of level I and II studies. Arthroscopy. 2013; 29(9):1579-88.

11. Madry H, Grün U, Knutsen G. Cartilage repair and joint preservation. Deutsches Ärzteblatt International. 2011;108(40):669-77.

12. Özmeriç A, Alemdaroğlu KB, Aydoğan NH. Treatment for cartilage injuries of the knee with a new treatment algorithm. World J Orthop. 2014;18(5):677-84.

13. Farr J, Cole B, Dhawan A, Kercher J, Sherman S. Clinical cartilage restoration. Evolution and overview. Clin Orthop Relat Res. 2011;469:2696-705.

14. Oussedik S, Tsitskaris K, Parker D. Treatment of articular cartilage lesions of the knee by microfracture or autologous chondrocyte implantation: a systematic review. Arthroscopy. 2015;31(4):732-44.

15. Jakobsen RB, Engebretsen L, Slauterbeck JR. An analysis of the quality of cartilage repair studies. J Bone Joint Surg Am. 2005;87(10):2232-9.

16. Hurst JM, Steadman JR, O'Brien L, Rodkey WG, Briggs KK. Rehabilitation following microfracture for chondral injury in the knee. Clin J Sport Med. 2010;29:257-65.
17. Wondrasch B, Årøen A, Røtterud JH, Høysveen T, Bølstad K, Risberg MA. The feasibility of a 3-month active rehabilitation program for patients with knee full-thickness articular cartilage lesions: the oslo cartilage active rehabilitation and education study. J Orthop Sports Phys Ther. 2013;43(5):310-24.

18. Safran MR, Seiber K. The evidence for surgical repair of articular cartilage in the knee. J Am Acad Orthop Surg. 2010;18(5):259-66.

19. Williams 3rd JR, Harnly HW. Microfracture: indications, technique, and results. AAOS Instructional Course Lectures. 2007;56:419-28.

20. Bekkers JEJ, Inklaar M, Saris DBF. Treatment selection in articular cartilage lesions of the knee: a systematic review. Am J Sports Med. 2009;37:148S-55.

21. Strauss EJ, Barker JU, Kercher JS, Cole BJ, Mithoefer K. Augmentation strategies following the microfracture technique for repair of focal chondral defects. Cartilage. 2010;1(2):145-52.

22. Steadman JR, Briggs KK, Rodrigo JJ, Kocher MS, Gill TJ, Rodkey WG. Outcomes of microfracture for traumatic chondral defects of the knee: average 11-year follow-up. Arthroscopy. 2003;19(5):477-84.

23. Blevins FT, Steadman JR, Rodrigo JJ, Silliman J. Treatment of articular cartilage defects in athletes: an analysis of functional outcome and lesion appearance. Orthopedics. 1998;21:761-8.

24. Mithoefer K, Williams 3rd RJ, Warren RF, Potter H, Spock C, Jones E, et al. The microfracture technique for the treatment of articular cartilage lesions in the knee. A prospective cohort study. J Bone Joint Surg Am. 2005;87:1911-20.

25. Mithoefer K, McAdams T, Williams RJ, Kreuz PC, Mandelbaum BR. Clinical Efficacy of the Microfracture Technique for Articular Cartilage Repair in the Knee. An Evidence-Based Systematic Analysis. Am J Sports Med. 2009;37(10): 2053-63.

26. Behery O, Siston RA, Harris JD, Flanigan D. Treatment of cartilage defects of the knee: expanding on the existing algorithm. Clin J Sport Med. 2014;24:21-30.

27. Gudas R, Stankevicius E, Monastyreckiene E, Pranys D, Kalesinskas RJ. Osteochondral autologous transplantation versus microfracture for the treatment of articular cartilage defects in the knee joint in athletes. Knee Surg Sports Traumatol Arthrosc. 2006;14:834-42.

28. Miller BS, Steadman JR, Briggs KK, Rodrigo JJ, Rodkey WG. Patient satisfaction and outcome after microfracture of the degenerative knee. J Knee Surg. 2004;17(1):13-7.

29. Asik M, Ciftci F, Sen C, Erdil M, Atalar A. The microfracture technique for the treatment of full-thickness articular cartilage lesions of the knee: midterm results. Arthroscopy. 2008;24:1214-20.

30. de Windt T, Bekkers JEJ, Creemers LB, Dhert WJA, Saris DBF. Patient profiling in cartilage regeneration - prognostic factors determining success of treatment for cartilage defects. Am J Sports Med. 2009;37:58S-62.

31. Negrin L, Kutscha-Lissberg F, Gartlehner G, Vecsei V. Clinical outcome after microfracture of the knee: a meta-analysis of before/after-data of controlled studies. Int Orthop. 2011;36:43-50.

32. Mundi R, Bedi A, Chow L, Crouch S, Simunovic N, Sibilsky Enselman E, Ayeni $\mathrm{OR}$. Cartilage restoration of the knee: a systematic review and meta-analysis of level 1 studies. Am J Sports Med. 2015. XX(X).

33. Randsborg P-H, Brinchmann J, Løken S, Hanvold HA, Aae TF, Årøen A. Focal cartilage defects in the knee -a randomized controlled trial comparing autologous chondrocyte implantation with arthroscopic debridement. BMC Musculoskelet Disord. 2016;17:117.

34. Collins N, Misra D, Felson DT, Crossley KM, Roos EM. Measures of knee function. Arthritis Care Res. 2011;63(11):S208-28.

35. Kellgren JH, Lawrence JS. Radiological assessment of osteo-arthrosis. Ann Rheum Dis. 1957;16(4):494-502.

36. Peterfy C, Li J, Zaim S, Duryea J, Lynch J, Miaux Y, Yu W, Genant HK. Comparison of fixed-flexion positioning with fluoroscopic semi-flexed positioning for quantifying radiographic joint-space width in the knee: testretest reproducibility. Skeletal Radiol. 2003;32(3):128-32.

37. Saris D, Price A, Widuchowski W, Bertrand-Marchand M, Caron J, Drogset JO, Emans P, Podskubka A, Tsuchida A, Kili S, Levine D, Brittberg M. Matrixapplied characterized autologous cultured chondrocytes versus microfracture: two-year follow-up of a prospective randomized trial. Am J Sports Med. 2014;42(6):1384-94.

38. Ulstein S, Årøen A, Røtterud JH, Løken S, Engebretsen L, Heir S. Microfracture technique versus osteochondral autologous transplantation mosaicplasty in patients with articular chondral lesions of the knee: a prospective randomized trial with long-term follow-up. Knee Surg Sports Traumatol Arthrosc. 2014;22(6):1207-15.

39. Brittberg M, Winalski CS. Evaluation of cartilage injuries and repair. J Bone Joint Surg Am. 2003;85(-A(Suppl 2)):58-69. 
40. Årøen A, Røtterud JH, Sivertsen EA. Agreement in arthroscopic and arthrotomy assessment of full-thickness articular cartilage lesions of the knee in a clinical setting in 33 consecutive patients. Cartilage. 2013;4(3):214-8.

41. Ravnihar K, Barlič A, Drobnič M. Effect of intra-articular local anesthesia on articular cartilage in the knee. Arthroscopy. 2014;30(5):607-12.

42. Chu CR, Coyle CH, Chu CT, Szczodry M, Seshadri V, Karpie JC, Cieslak KM, Pringle EK. In vivo effects of single intra-articular injection of 0.5\% bupivacaine on articular cartilage. J Bone Joint Surg Am. 2010;92(3):599-608

43. Lo IK, Sciore P, Chung M, Liang S, Boorman RB, Thornton GM, Rattner JB, Muldrew K. Local anesthetics induce chondrocyte death in bovine articular cartilage disks in a dose- and duration-dependent manner. Arthroscopy. 2009;25(7):707-15.

44. Steadman JR, Rodkey WG, Briggs KK. Microfracture to treat full-thickness chondral defects: surgical technique, rehabilitation, and outcomes. J Knee Surg. 2002;15(3):170-6.

45. Steadman JR, Rodkey WG, Rodrigo JJ. Microfracture: Surgical Technique and Rehabilitation to Treat Chondral Defects. Clin Orthop Relat Res. 2001;391S:S362-9.

46. Steadman JR, Rodkey WG, Singleton SB, Briggs KK. Microfracture technique for full-thickness chondral defects: Technique and clinical results. Oper Tech Orthop. 1997;7(4):300-4.

47. Roos EM, Roos HP, Lohmander LS, Ekdahl C, Beynnon BD. Knee Injury and Osteoarthritis Outcome Score (KOOS) - development of a self-administered outcome measure. J Orthop Sports Phys Ther. 1998:28(2):88-96.

48. Reid A, Birmingham B, Stratford PW, et al. Hop testing provides a reliable and valid outcome measure during rehabilitation after cruciate ligament reconstruction. Phys Ther. 2007;87:337-49.

49. Team RC. A language and environment for statistical computing. Vienna, Austria: R Foundation for Statistical Computing. 2014.

50. Engelhart L, Nelson L, Lewis S, Mordin M, Demuro-Mercon C, Uddin S, McLeod L, Cole B, Farr J. Validation of the Knee Injury and Osteoarthritis Outcome Score subscales for patients with articular cartilage lesions of the knee. Am J Sports Med. 2012;40(10):2264-72.

51. Roos EM, Toksvig-Larsen S. Knee injury and Osteoarthritis Outcome Score (KOOS) - validation and comparison to the WOMAC in total knee replacement. Health Qual Live Outcomes. 2003;1:1-10.

\section{Submit your next manuscript to BioMed Central and we will help you at every step:}

- We accept pre-submission inquiries

- Our selector tool helps you to find the most relevant journal

- We provide round the clock customer support

- Convenient online submission

- Thorough peer review

- Inclusion in PubMed and all major indexing services

- Maximum visibility for your research

Submit your manuscript at www.biomedcentral.com/submit

) Biomed Central 